\title{
Hydrogel-Based Protein Microchips: Manufacturing, Properties, and Applications
}

BioTechniques 34:1008-1022 (May 2003)

\author{
A.Yu. Rubina, E.I. Dementie- \\ va, A.A. Stomakhin, \\ E.L. Darii, S.V. Pan'kov, \\ V.E. Barsky, S.M. Ivanov, \\ E.V. Konovalova, and \\ A.D. Mirzabekov \\ Russian Academy of Sciences, \\ Moscow, Russia
}

\section{ABSTRACT}

Here a simple, reproducible, and versatile method is described for manufacturing protein and ligand chips. The photo-induced copolymerization of acrylamidebased gel monomers with different probes (oligonucleotides, DNA, proteins, and lowmolecular ligands) modified by the introduction of methacrylic groups takes place in drops on a glass or silicone surface. All probes are uniformly and chemically fixed with a high yield within the whole volume of hydrogel semispherical chip elements that are chemically attached to the surface. Purified enzymes, antibodies, antigens, and other proteins, as well as complex protein mixtures such as cell lysates, were immobilized on a chip. Avidin- and oligohistidinetagged proteins can be immobilized within biotin-and Ni-nitrilotriacetic acid-modified gel elements. Most gel-immobilized proteins maintain their biological properties for at least six months. Fluorescence and chemiluminescence microscopy were used as efficient methods for the quantitative analysis of the microchips. Direct on-chip matrix-assisted laser desorption ionization-time of flight mass spectrometry was used for the qualitative identification of interacting molecules and to analyze tryptic peptides after the digestion of proteins in individual gel elements. We also demonstrate other useful properties of protein microchips and their application to proteomics and diagnostics.

\section{INTRODUCTION}

Microarrays of immobilized DNA and proteins are becoming efficient instruments in research and practical applications (1-4). DNA microchips are more advanced than protein microchips due to the relative simplicity of DNA structure; however, protein microchip technology is developing rapidly $(5,6)$. The protein chips allow one to assay simultaneously a large number of specific proteins, protein-binding agents, and enzymatic reactions in a single experiment.

Numerous supports are used for the immobilization of biomolecules on biochips, such as uncoated and coated glass, different membranes, gold or gold covered with sulfhydryl groupcontaining spacers, microchannels, and hydrogels $(2,7)$. However, there are several complications encountered with the preparation of protein chips. Proteins can denature in the interface between the water solution and solid surface used for immobilization. Protein molecules have a tendency to stick to a solid surface preferentially by one side that could shield an active site. When placed close to each other, protein molecules tend to aggregate. At the same time, the concentration of immobilized proteins should be high enough to provide the needed sensitivity. The use of a hydrogel support for the immobilization of proteins allows one to avoid most of these complications.

In 1989, we began to develop the oligonucleotide microchips and demonstrated that 3-D polyacrylamide hydrogels provide a convenient support for the immobilization of oligonucleotides (8). Similar gels were later used to manufacture DNA and protein microchips $(9,10)$. The 3 -D gel support provides essential advantages as com- pared with 2-D surface immobilization (3). Gel biochips show a high immobilization capacity simultaneously with distant spacing of immobilized molecules. The gel consists of about $95 \%$ water, which provides aqueous surroundings, allows accessibility of the immobilized molecules from all sides, prevents protein-protein contacts, and results in a high sensitivity of on-chip analysis. Note that each gel element of the microchip can be used as an individual nanoliter test tube to carry out chemical and enzymatic reactions.

The first generation of gel-based biochips was manufactured by a rather complicated procedure that consisted of many consecutive steps: photolitography of gel matrix and its chemical activation; precise robotic application of the solution of chemically activated probe on the gel surface; and chemical binding to the gel. This technology required a complicated robot, was difficult to scale up, and had other disadvantages. Later, a copolymerization procedure was introduced for a simpler and more straightforward incorporation of different compounds into the gel elements of the microchips (11-14). The first-generation oligonucleotide gel microchips have been used in many applications (see Reference 15), and protein microchips have been used to carry out immunoassays, on-chip enzymatic reactions, and kinetic measurements (9).

In this report, we describe a simple and reproducible procedure for the large-scale manufacturing of immobilized microarray of gel elements (IMAGE) chips with different proteins and ligands. The main step is photo-induced copolymerization of acrylamidebased gel monomers with proteins, oligonucleotides, DNA, or low-molecular ligands modified by the introduction 
of methacrylic groups in miniature drops. The applications of these protein chips for qualitative and quantitative studies are also investigated.

\section{MATERIALS AND METHODS}

Purified barnase and barstar were provided by Dr. G.I. Yakovlev [Engelhardt Institute of Molecular Biology (EIMB), Moscow, Russia]. Recombinant human embryo cells expressing barstar were provided by Dr. V.S. Prassolov (EIMB). The cells, line 293, were transfected with a recombinant plasmid obtained by the introduction of barstar gene in the DNA of a retroviral vector.

Prostate-specific antigen (PSA), monoclonal antibodies to PSA, and blood serum samples were provided by the Scientific-Research Institute of Experimental Diagnostics and Tumor Therapy of the Russian Oncological Scientific Center (Moscow, Russia). Insulin, HRP (RZ 3.0), protein A, L-aspartate aminotransferase, monoclonal and polyclonal antibodies to HRP, human IgG, and trypsin (sequencing grade) were purchased from Sigma (St. Louis, MO, USA); avidin and BSA from Calbiochem (San Diego, CA, USA); lysozyme (chicken egg white) from Serva (Heidelberg, Germany); peroxidase chemiluminescent substrates (SuperSignal ${ }^{\circledR}$ ELISA Pico Stable Peroxide and Luminol Enhancer solutions) from Pierce Chemical (Rockford, IL, USA); Sephadex ${ }^{\circledR}$ G-25 coarse from Amersham Biosciences (Piscataway, NJ, USA); Micro Bio-Spin chromatography columns from Bio-Rad Laboratories (Hercules, CA, USA); Texas Red sulfonyl chloride from Molecular Probes (Eugene, OR, USA); and glass slides for the fabrication of microarrays (2947 Micro Slides) from Corning (Corning, NY, USA).

Microchips assays were carried out in $25-\mu \mathrm{L}$ reaction chambers (in situ frames; Eppendorf Scientific, Westbury, NY, USA). Other chemical reagents were obtained from commercial suppliers and used without further purification.

Oligonucleotides were synthesized on a 394 DNA/RNA synthesizer (Applied Biosystems, Foster City, CA, USA). Mass spectrometric analysis was carried out with a matrix-assisted laser desorption ionization-time of flight (MALDI-TOF) mass spectrometer (KOMPACT MALDI 4; Kratos Analytical, Chestnut Ridge, NY, USA) using sinapinic acid or 2-amino-5-nitropyridine (Aldrich Chemical, Milwaukee, WI, USA) as matrix. Spectral measurements were carried out on a V-550 spectrophotometer (Jasco, Tokyo, Japan).

\section{Incorporation of Methacrylic \\ Groups into Proteins}

Protein solution $(100 \mu \mathrm{L}$ at $20 \mu \mathrm{M})$ in $0.01 \mathrm{M}$ borate buffer, $\mathrm{pH} 9.3$, was mixed with $20 \mu \mathrm{L}$ of a $0.1-10 \mathrm{mM}$ solution of $N$-hydroxysuccinimide ester of 6-methacrylaminohexanoic acid in dimethyl formamide (DMF), and the mixture was stirred from 0.5 to $2 \mathrm{~h}$ at room temperature. The protein:modifier molar ratio was varied from 1:1 to $1: 100$. The modified proteins were purified on a Micro Bio-Spin column with Sephadex G-25 or used for copolymerization in the reaction mixture without purification. The number of methacrylic groups introduced into proteins with molecular masses up to $60 \mathrm{kDa}$ was determined by MALDI mass spectra.

\section{Fabrication of Microchips}

Glass slides for the fabrication of second-generation microchips were treated with Bind-Silane, washed, and dried. Solution of copolymerization mixture containing $3.7 \%$ methacrylamide $(\mathrm{w} / \mathrm{v}), \quad 0.3 \% \quad N, N^{\prime}$-methylenebisacrylamide (w/v), 50\% glycerol $(\mathrm{v} / \mathrm{v})$, and modified protein $(0.5 \mathrm{mg} / \mathrm{mL}$ in $0.01 \mathrm{M}$ PBS containing $150 \mathrm{mM}$ $\mathrm{NaCl}, \mathrm{pH}$ 7.2) were transferred to the wells of a 384-well microplate (Genetix, New Milton, UK) and spotted by a robot pin [(GMS 417 Arrayer; Affymetrix, Santa Clara, CA, USA) or (Qarray; Genetix)] or piezoelectric head (GeSiM, Dresden, Germany) onto the surface of a glass slide. The standard gel elements were $200 \mu \mathrm{m}$ in diameter when applied with a $300-\mu \mathrm{m}$ robot pin. The polymerization of gel arrays was carried out under UV light with a maximal wavelength of $350 \mathrm{~nm}$, irradiation intensity at $0.06 \mu \mathrm{W} / \mathrm{cm}^{2}$ (Sylvania GTE lamp, F15T8/350 BL, 
$15 \mathrm{~W}$ power, $8 \mathrm{~cm}$ distance from the lamp), for $20 \mathrm{~min}$ at $20^{\circ} \mathrm{C}$ in dry nitrogen. After polymerization, the microchips were washed with $50 \mathrm{~mL} 0.01$ $\mathrm{M}$ PBS, $\mathrm{pH} 7.2$, containing $0.1 \%$ Tween ${ }^{\circledR} 20$ (PBST) and stored in 0.01 M PBS containing 20\%-40\% glycerol at $10^{\circ} \mathrm{C}$. Third-generation microchips were provided by Biochip-IMB, Ltd. (Moscow, Russia).

\section{Labeling with Fluorescent Dyes}

To label proteins at amino groups, 10 $\mu \mathrm{L}$ of solution of Texas Red sulfonyl chloride or $\mathrm{Cy}^{\mathrm{TM}} 3$ succinimide ester (protein:dye molar ratio, 1:10) in acetonitrile or DMF were added to $500 \mu \mathrm{L}$ of protein solution $(5 \mathrm{mg} / \mathrm{mL})$ in borate buffer, $\mathrm{pH}$ 9.3, and the mixture was stirred for $1-2 \mathrm{~h}$ at room temperature. Labeled protein was purified on Sephadex G-25. The Texas Red or Cy3:protein molar ratios were determined by the absorbance at 280 and 595 or $545 \mathrm{~nm}$, respectively, to be near 1.0.

\section{Microchip Analysis}

Fluorescence and chemiluminescence measurements. Quantitative fluorescence measurements were carried out with a four-wavelength fluorescence microscope and portable laser microscopes (both from Biochip-IMB Ltd.). The microscopes were equipped with a cooled charge-coupled device (CCD) camera, temperature-controlled table, and computer with special software for the registration of fluorescence signal from each gel pad, monitoring real-time kinetics of fluorescence intensity, and processing the data $(16,17)$. The field of view of the research-grade microscope covers about 2000 gel pads. It can carry out measurements automatically and simultaneously at four wavelengths, at various changing temperatures in real time, with the dried microchip or microchip covered with solution in a reaction chamber. Portable laser microscope can measure quantitatively and simultaneously fluorescence intensities of the $4 \times$ $6 \mathrm{~mm}$ area of a dried microchip, containing up to 200 standard gel elements that are $100 \mu \mathrm{m}$ in diameter and spaced $200 \mu \mathrm{m}$ from each other. The measurements with Texas Red and Cy3 dyes were carried out using 580/630 and $535 / 590 \mathrm{~nm}$ excitation/emission filters, respectively. For GFP, 425/530 nm filters were used. Fluorescence intensities (I) from biochip elements were calculated by the formula:

$$
I=(F-B) / B
$$

where $F$ is the integral fluorescence calculated for the image area occupied by the gel pad, and $B$ is the integral background calculated for the equal area taken in the close vicinity of the gel pad. As the background $B$ signal is proportional to the local excitation intensity, the use of the integral signal $I$ allowed us to compensate for the sensitivity variations across the image field (4). The fluorescence background from the gel elements did not differ from that of glass surface. Peroxidase-catalyzed luminol chemiluminescence was measured using the same microscopes with the excitation lamp switched off.

MALDI-TOF MS. The microchips were prepared on silicon slides. Avidin, monoclonal antibodies to insulin (both at $0.1 \mathrm{mg} / \mathrm{mL}$ ), and nitrilotriacetic acid (NTA) modified with an $N$-methacryloyl group $(5 \mathrm{mg} / \mathrm{mL})$ were immobilized within gel elements of microchips. After washing, biotinylated insulin, lysozyme, HRP, and BSA $(1 \mathrm{mg} / \mathrm{mL}$ in PBS) were applied to gel elements with immobilized avidin, and insulin (0.5 $\mathrm{mg} / \mathrm{mL}$ in PBS) was applied to gel elements with immobilized antibodies. Gel elements with immobilized NTA were treated with $0.05 \mathrm{M} \mathrm{NiSO}_{4}$, and a solution of recombinant GFP containing an His $_{6}$-fragment $(4 \mathrm{mg} / \mathrm{mL}$ ) was applied. Empty gel elements were used as a control after their treatment with the same protein solutions and washing. The chips were incubated for $2 \mathrm{~h}$ at room temperature. After washing the chip with PBST and water, $1 \mu \mathrm{L}$ saturated solution of sinapinic acid was added to each gel element, and the chip was kept in a moist chamber at room temperature for $20 \mathrm{~min}$, air dried, and used for the MALDI-TOF MS analysis of each gel element.

\section{Degree of Immobilization}

The degree of immobilization of a protein within a gel was determined with fluorescently labeled proteins im- mobilized on a chip. The chip was washed with PBST buffer, $\mathrm{pH}$ 7.2, until the fluorescence signal from the chip remained constant. The degree of immobilization was calculated as the ratio of the fluorescence signals before and after washing.

\section{Printing Uniformity and Protein Chip Reproducibility}

The printing uniformity was evaluated by forming the $10 \times 10$ arrays of gel elements with a polymerization mixture containing Texas Red labeled protein $\mathrm{A}$, according to the program supplied with the robot. Following the printing, the array was polymerized, washed out, dried, and the fluorescence image was processed to determine the relative volumes of the gel elements. The volumes were evaluated as integral fluorescence signals of gel elements calculated using Equation 1. The average fluorescence signals and standard deviations were calculated for each array and for a series of different slides.

\section{Diffusion of Proteins inside Gel Pads}

A $10-\mu \mathrm{M}$ solution of Cy3-labeled human immunoglobulin $\mathrm{G}$ or Cy3-labeled barnase in 0.01 M PBS was applied on a chip containing gel pads with no immobilized probes. The kinetics of the diffusion of the labeled proteins into the gel pads was recorded by measuring automatically the fluorescence intensity for each gel pad every minute for $1-2 \mathrm{~h}$ at room temperature.

\section{Determination of Enzymatic Activi- ty of Chip-Immobilized Proteins}

Barnase was immobilized on a chip with gel elements that were $0.6 \mathrm{~mm}$ in diameter. The concentration of the immobilized barnase in the gel was 0.1 $\mathrm{mg} / \mathrm{mL}$. An aqueous solution of oligonucleotide $5^{\prime}$-TTTT-(ribo-UUU)TTTTT-3' $(1.0 \mu \mathrm{M})$ or 5'-TTGAA-(riboG)-ACT-3' $(0.5 \mu \mathrm{M})$ was applied on the microchip, $10 \mu \mathrm{L}$ per gel element, and the chip was kept at room temperature or at $2{ }^{\circ} \mathrm{C}$. At different time intervals, MALDI-TOF mass spectra were obtained directly from gel elements.

HRP. The enzymatic activity was determined as chemiluminescent signal 
upon the oxidation of luminol with $\mathrm{H}_{2} \mathrm{O}_{2}$ in the presence of the enhancer. A mixture of $15 \mu \mathrm{L}$ hydrogen peroxide and $15 \mu \mathrm{L}$ luminol enhancer solutions was applied to a microchip in the reaction chamber, and the chemiluminescent signal was recorded for 10-60 s. The percentage of activity after immobilization was calculated as the ratio of the chemiluminescence signal from the gel pad after polymerization and washing to the signal from the gel pad containing non-immobilized peroxidase with the same concentration that was diffused inside the gel.

\section{Interactions of Chip-Immobilized Proteins}

Assays on the chips were carried out in 25- $\mu \mathrm{L}$ transparent reaction chambers. Solutions of fluorescently labeled proteins $\left(10^{-5}-10^{-9} \mathrm{M}\right)$ or oligonucleotides $\left(10^{-5}-10^{-6} \mathrm{M}\right)$ were applied to microchips with immobilized protein and incubated at a constant temperature for 1-24 h. After the incubation, the microchips were dismounted from the reaction chambers, washed twice for 40 min with $50 \mathrm{~mL} \mathrm{PBST}$, air dried, and used for fluorescent measurements.

Immunoassay of PSA. Monoclonal antibodies to PSA were immobilized on $200 \mu \mathrm{m}$ gel pads of microchips $(0.1 \mathrm{mg}$ proteins $/ \mathrm{mL}$ gel). The chips were washed with PBST for $2 \mathrm{~h}$ at room temperature. Blocking solution (1\% BSA, $5 \%$ sucrose or $0.5 \%$ polyvinyl alcohol, $m, 50000$, in PBS, pH 7.2) was applied, and the chips were kept for $2 \mathrm{~h}$ at room temperature. After blocking, solutions of PSA $(0.5-100 \mathrm{ng} / \mathrm{mL})$ in PBS or blood sera diluted 2-10 times in PBS were applied to the chips, and they were kept overnight in a moist chamber at $10^{\circ} \mathrm{C}$. The chips were washed with PBST for $40 \mathrm{~min}$ at room temperature and treated with a $20 \mu \mathrm{g} / \mathrm{mL}$ solution of secondary monoclonal antibodies to PSA labeled with $\mathrm{Cy} 3$ for $1 \mathrm{~h}$ at room temperature. After washing with PBST, fluorescence signals from the gel elements were recorded. Fluorescence signals were plotted versus PSA concentrations to measure PSA in blood serum samples.

Quantitative assay of barstar in cell lysates. The recombinant barstar was expressed in human embryo cells transformed with the plasmid contain- ing the barstar gene. The cells were lysed, polyethyleneimine $(0.05 \%)$ was added, and DNA precipitate was removed by centrifugation at $10000 \times g$ for $30 \mathrm{~min}$. Known amounts of barstar were added to the aliquots of control lysate. The lysates were immobilized on a microchip, and the chip was developed with Texas Red-labeled barnase with $(20 \mu \mathrm{g} / \mathrm{mL}$ in borate buffer, $\mathrm{pH}$ 9.3). After washing and drying, fluorescent signals from the labeled bound barnase were measured. The calibration curve was obtained by plotting fluorescent signals against concentrations of barstar in the chip-immobilized control lysates.

Proteolitic hydrolysis of proteins in microchip gel elements. Microchips with lysozyme-containing gel elements $(1 \mathrm{mg} / \mathrm{mL}$ gel) $0.6 \mathrm{~mm}$ in diameter on silicon slides were prepared. For lysozyme denaturation, $1 \mu \mathrm{L} 50 \mathrm{mM}$ Tris- $\mathrm{HCl}, \mathrm{pH}$ 8.0, $5 \mathrm{mM}$ dithiothreitol, and $6 \mathrm{M}$ guanidine chloride were added to each gel element, and the chip was incubated in a moist chamber at $65^{\circ} \mathrm{C}$ for $4 \mathrm{~h}$. The chip was washed briefly with $0.2 \mathrm{M}$ ammonium bicarbonate at $65^{\circ} \mathrm{C}$ and dried at $37^{\circ} \mathrm{C}$. One microliter of trypsin solution (sequencing grade) in $0.2 \mathrm{M}$ ammonium bicarbonate $(25$ $\mu \mathrm{g} / \mathrm{mL}$; the protease:protein ratio, 1:20) was added in three steps to the dried gel elements, and the chip was kept at $37^{\circ} \mathrm{C}$ for $24 \mathrm{~h}$ in a sealed humid chamber to avoid evaporation. The reaction was stopped by the addition of $0.1 \%$ trifluoroacetic acid to each gel element, and the chip was dried at $37^{\circ} \mathrm{C}$ and used for MALDI-TOF MS analysis.

\section{RESULTS}

\section{Manufacturing and Characteriza- tion of Protein Microchips}

The manufacturing of second-generation microchips consists of three steps: modification of proteins with polymerization monomer; the robotic application of drops of the polymerization mixture with a pin or jet printer on a glass slide; and the photo-induced copolymerization of modified proteins with gel monomers. The general view and fluorescence images of microchips are shown in Figure 1, panels A and B. 
The polyacrylamide gel and its different modified forms have been used as a support for the protein immobilization by copolymerization.

In this work, the proteins were modified at their $\mathrm{NH}_{2}$ - and $\mathrm{SH}$-groups by acylation with $N$-hydroxysuccinimide ester of 6-( $N$-methacryloyl)-aminohexanoic acid (MAOSu) (18). The reaction was carried out in an aqueousorganic medium and occurred with a high yield. The variation of the protein:modifier molar ratio and reaction time allowed us to obtain proteins with a different number of methacrylic groups (e.g., from one to nine groups in the case of barnase, as determined by MALDI-TOF MS). Note that proteins can be used in copolymerization without any purification step after the modification reaction - an advantage that simplifies the manufacturing procedure. We tested compounds with other unsaturated groups, but modification by the introduction of methacrylic group appeared to be optimal.

Three different UV lamps with maximum wavelengths at 254, 312, and 350 $\mathrm{nm}$ have been tested to induce the photo-polymerization of the gel. At lower wavelengths, the yield of the polymerization was higher, but the gel porosity was lower, and protein inactivation was more dramatic. Temperature, polymerization conditions, and the nature of gelforming monomer have a substantial effect on the properties of the resulting gel. The conditions for the immobilization of proteins were chosen to maintain their biological properties; that is, polymerization at room temperature for a shorter period of time and illumination with a UV lamp with a maximum wavelength $350 \mathrm{~nm}$. The use of the longer UV wavelength was facilitated by the fact that methacrylamide has a higher molar absorption at this wavelength than acrylamide.

Copolymerization appeared to proceed with high efficiency, with a significant proportion of free monomers and monomers attached to protein molecules involved in gel formation. The degree of the immobilization of the proteins under selected conditions did not depend essentially on the amount of incorporated methacrylic groups. Barnase containing from one to five attached methacrylic groups per molecule was immobilized in
Table 1. Degree of Immobilization of Proteins in Gel Elements of the Microchips Manufactured by Copolymerization Method

\begin{tabular}{|lcc|}
\hline Protein & $\boldsymbol{m}$ (kDa) & Immobilization (\%) \\
\hline Antibodies (human immunoglobulin G, & 150 & $40-55$ \\
polyclonal antibodies to HRP, monoclonal & & \\
antibodies to PSA & & 62 \\
L-aspartate aminotransferase & 90 & 65 \\
BSA & 67 & 40 \\
HRP & 44 & 70 \\
Protein A & 42 & 58 \\
B-Lactoglobulin & 18 & $70-75$ \\
Barnasea & 12 & \\
aBarnase contained 1-5 methacrylic groups. & & \\
\hline
\end{tabular}

the same range of $70 \%-75 \%$. As can be seen from Table 1 , the efficiency of the immobilization depended more on the nature of proteins than on their molecular mass and constituted $40 \%-75 \%$ for proteins in the range from $12 \mathrm{kDa}$ (barnase) to 150 $\mathrm{kDa}$ (antibodies).

The manufacturing of third-generation microchips is simpler and consists of two steps, the protein modification and incorporation into gel matrix by copolymerization occurring simultaneously [Biochip-IMB, Ltd. (19)]. Protein microchips of the second and the third generations are very similar in properties, including the degree of protein immobilization.

The immobilization of proteins in the semispherical gel elements occurs simultaneously with gel polymerization and therefore results in the formation of a uniform structure, in which the protein is distributed throughout the whole volume of the gel element. The 3-D images of the gel elements containing fluorescently labeled immobilized proteins and the images of gel pads after the interaction with fluorescence probes have the same

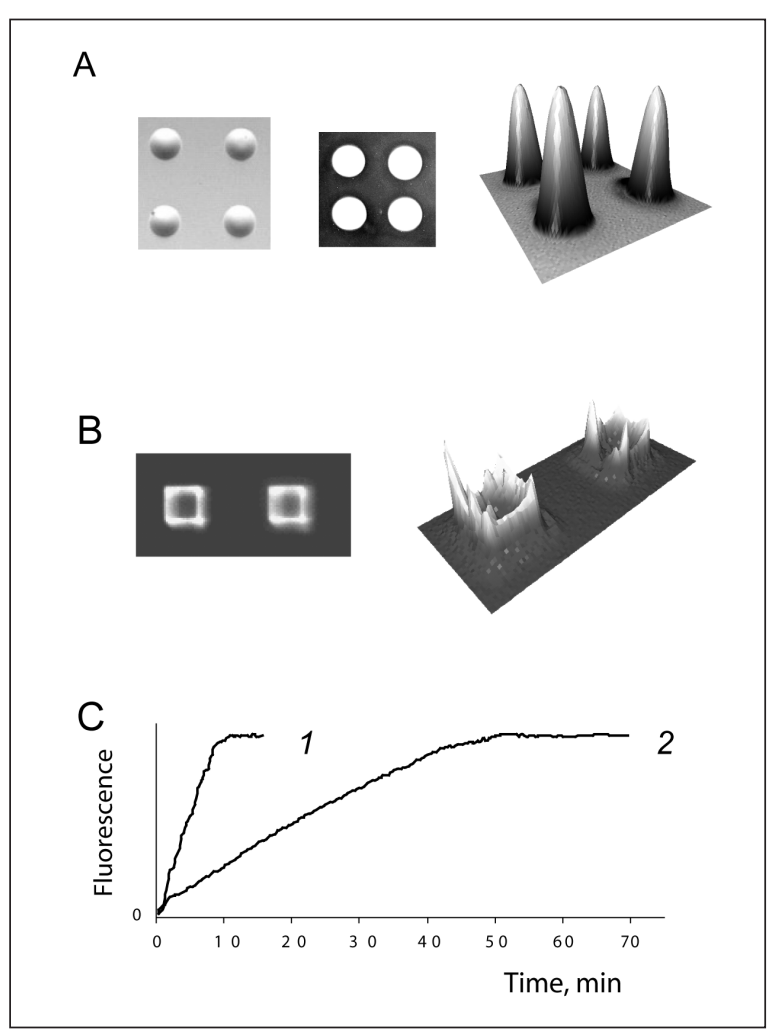

Figure 1. Properties of the first-generation and second-generation microchips. The second-generation (IMAGE) microchip, general view obtained with a CCD camera in transmitted light and 2- and 3-D images of fluorescence signals from the gel elements (A). First-generation microchip, 2- and 3-D images of fluorescence signals (B). Kinetics of the diffusion of Cy3-labeled barnase, $12.3 \mathrm{kDa}(1)$, and antibodies, $150 \mathrm{kDa}$, (2) into gel pads (C). The images were obtained using IMAGE chip viewer computer software developed at the Center of Biological Microchips, Moscow, Russia. 
the robotic application of the protein solutions on the surface of preformed pads. This heterogeneity was also found to worsen significantly the properties of the first-generation microchips, namely the reproducibility and accuracy of the results.

The protein biochips described in this work have high porosity. When labeled antibodies $\left(M_{\mathrm{r}}, 150 \mathrm{kDa}\right)$ or barnase $(12 \mathrm{kDa})$ were allowed to penetrate into the gel at room temperature, the saturation of fluorescence signals was reached in 50 and $10 \mathrm{~min}$, respectively (Figure 1C).

The gel elements were stable enough to sustain boiling in water and buffer solutions for $10 \mathrm{~min}$ or $30-40$ PCR cycles of DNA amplification with temperature changes from $50^{\circ} \mathrm{C}$ to $95^{\circ} \mathrm{C}$. The gels can be stored either dry or wet. Most protein chips can be kept in a sealed humid chamber at $10^{\circ} \mathrm{C}$ for many months in the presence of $20 \%-40 \%$ glycerol. The microscopic examination of microchip elements did not reveal any gel deformation for at least six months.

Concentration range of gel-immobilized proteins and immobilization density. An advantage of gel-based microchips is the possibility to use immobilized substances in a wide interval of concentrations. The concentration

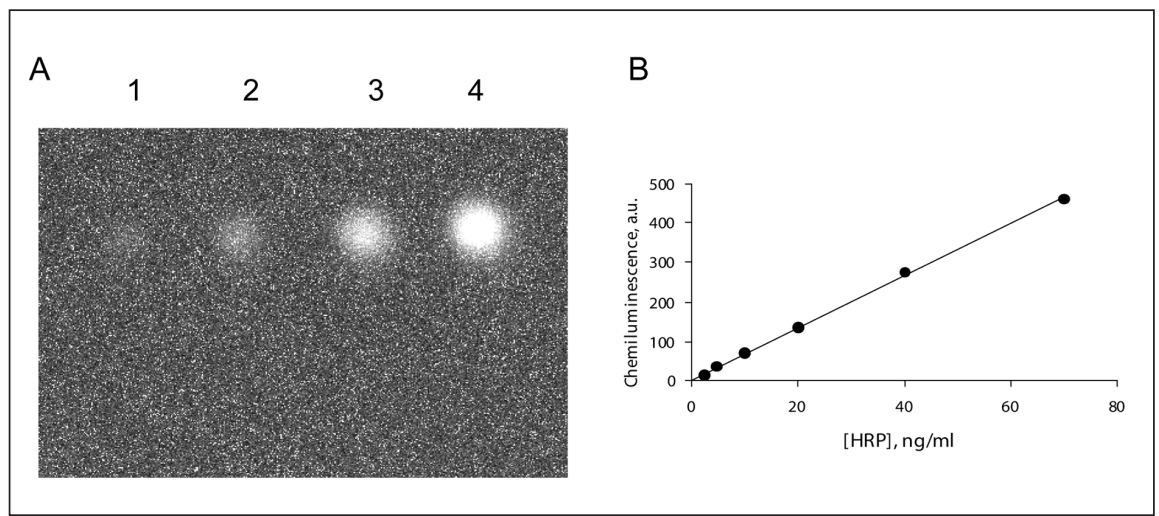

Figure 2. Direct immunoassay with chemiluminescent detection on a chip. The fluorescence images of a microchip with immobilized polyclonal antibodies to HRP 0.01 (1), 0.025 (2), 0.05 (3), and 0.1 (4) $\mathrm{mg} / \mathrm{mL}$ (upper row) and immobilized human IgG in the same concentrations (lower row, no visible signals) after the development with HRP $(2 \mathrm{ng} / \mathrm{mL})$ and chemiluminescent substrates were measured. The signals were accumulated for $60 \mathrm{~s} \mathrm{(A).} \mathrm{Dependence} \mathrm{of} \mathrm{chemiluminescence} \mathrm{intensity} \mathrm{on} \mathrm{the} \mathrm{concentra-}$ tion of HRP applied to the chip with immobilized antibodies $(0.1 \mathrm{mg}$ antibody $/ \mathrm{mL}$ gel $)(B)$.

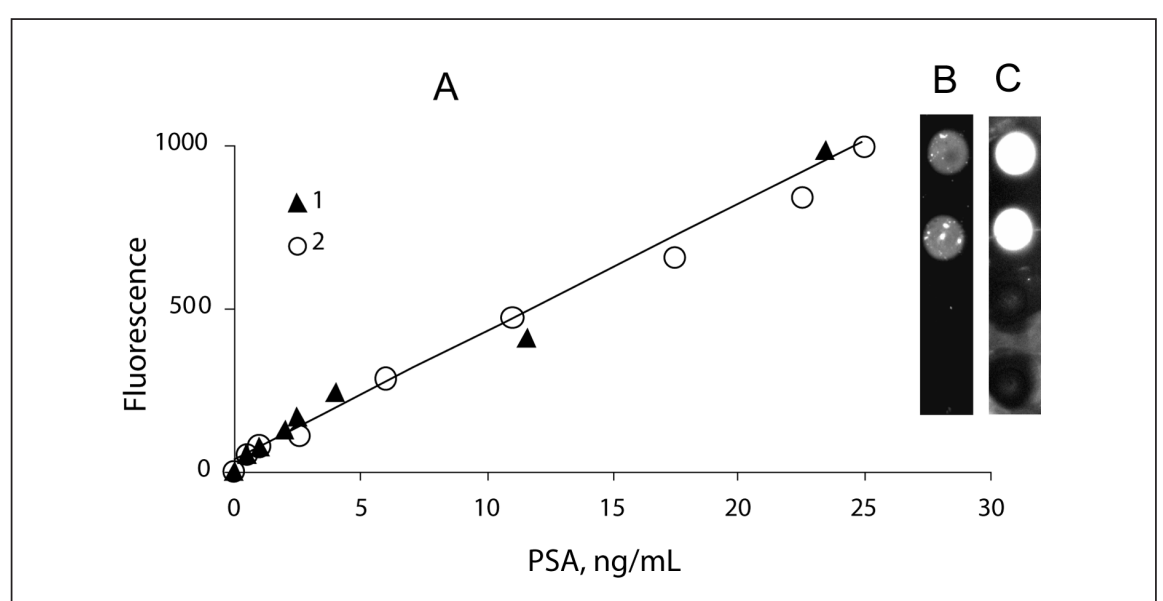

Figure 3. Biochip immunoassay of PSA. Fluorescent signal from gel elements with immobilized antibodies to PSA versus PSA concentration in solution after development with Cy3-labeled secondary antibodies. (A) Calibration curves for PSA quantification using a freshly prepared chip (1), and the same, after six months storage of the chip in humid chamber at $10^{\circ} \mathrm{C}(2)$. Fluorescent images of microchips for a healthy patient, $4 \mathrm{ng}$ PSA $/ \mathrm{mL}$ (B) and prostate cancer patient with an increased amount of PSA, 23 $\mathrm{ng} / \mathrm{mL}$ (C). range for antibodies immobilized within gel elements that are $200 \mu \mathrm{m}$ in diameter $(2 \mathrm{~nL}$ in volume) is $0.5-100$ fmol per gel element.

At our working concentration of immobilized antibodies in the gel 0.5 $\mathrm{mg} / \mathrm{mL}$, the average distance between the gel-immobilized molecules is about $1000 \AA$. Approximating the antibody molecules as microspheres that are 170 $\AA$ in diameter, this distance is significantly longer than the size of the molecule. Such intermolecular distance makes the immobilized molecules accessible for the interactions with large ligands, even for the formation of tertiary protein complexes in the case of sandwich immunoassay. Because of their fixed special position, the immobilized molecules do not interact either with each other or with hydrophobic glass surface, which eliminates protein aggregation and adsorption.

The total intensity of the fluorescent signal from a gel element is determined by the total amount of immobilized probe projected onto the surface occupied by the element. In the case of 3-D gel elements, the signal is several hundred times higher as compared to surface-immobilized probes. This follows from the calculations below.

Projection of a semi-spherical gel element $2 \mathrm{~nL}$ in volume is a circle that is $200 \mu \mathrm{m}$ in diameter. Let us assume that the average spacing between immobilized proteins is $250 \AA-1.5$ times more than $170 \AA$, the approximate diameter of the immunoglobulin molecule. Therefore, the ratio of the maximal density of immobilized proteins within a gel to the maximal density of proteins immobilized on the corresponding surface is about 2000 times. This value depends on the volume of gel element: the higher the volume, the higher the ratio of densities is in 3-D and 2-D elements.

Protein chip reproducibility. The fluorescence signals were measured in the $10 \times 10$ arrays of gel elements with immobilized Texas Red-labeled protein A after gel polymerization and washing. The variation of the fluorescence signal characterized the reproducibility of the volume of polymerization mixture delivered by the arrayer to each array in the set of slides and of the resulting amount of immobilized protein within 
gel elements. The coefficients of variation for the volumes of gel elements within one array and between different slides were $5 \%$ and $10 \%$, respectively.

\section{Methods for Microchip Analysis}

Three different methods that are usually applied for biochip analysis have been tested on IMAGE chips. Quantitative fluorescent analysis was carried out with two types of fluorescence microscopes, research and clinical ones, supplied with CCD cameras and the proper software $(16,17)$. The quantitative chemiluminescent analysis was performed with both microscopes with the illumination light switched off. The sensitivity of the instruments for both fluorescent and chemiluminescent measurements was $0.1-1$ amol, depending on the label.

Qualitative MALDI-TOF MS was carried out directly on individual gel elements (20). The chemical reactions or binding experiments were performed in individual gel pads of the microchips located on hydrophobic silicon surface. After the reactions, protein-protein and protein-ligand complexes were dissociated by treatment with MALDI-TOF matrix solution in the presence of different additives. Migration of the molecules from the inside of the gel pads onto their surface during the drying procedure made them available for direct MALDI-TOF mass monitoring. The microchip consisted of linearly arranged gel pads from 0.4 to $1 \mathrm{~mm}$ in diameter and spaced $3 \mathrm{~mm}$ from each other. The sensitivity of the instrument for the analysis of the proteins was $0.1-1$ pmol per sample depending on the protein. This microchip configuration and sensitivity were limited by the technical shortcomings of the KOMPACT MALDI 4 mass spectrometer and could be overcome by using other models.

\section{Antibody-Antigen Interaction on Microchips}

Direct immunoassay with immobilized antibodies. Several types of antigen-antibody interactions using different types of signal registration can be monitored using biochips with immobilized proteins. Protein A was immobilized on a microchip, and the chip was developed with human immunoglobulins labeled with Texas Red. Fluorescent signals that were directly proportional to the protein A concentration were observed (data not shown), indicating that immobilized protein A maintained its ability for the specific binding of ligands. Insulin was used for the analysis of direct antigenantibody interaction by both fluorescent and MALDI-TOF MS analysis. Antibodies to insulin were immobilized in the gel pads of the microchip, and the chip was incubated with Cy3-labeled insulin. Specific fluorescent signals directly proportional to the concentration of labeled insulin were measured using a fluorescent microscope. Mass spectrometry analysis directly from gel elements revealed the peak of molecular ion of insulin with $\mathrm{m} / \mathrm{z} 5730$ (data not shown).

Antibodies to HRP were immobilized on a chip, and the chip was developed with different concentrations of HRP and chemiluminescent peroxidase substrates (Figure 2). The chemiluminescence intensity was proportional to the HRP concentration, and as little as $2 \mathrm{ng} / \mathrm{mL}$ HRP can be detected after it binds to antibodies. The signals from the gel elements with immobilized nonspecific antibodies were not visible.

Sandwich immunoassay of PSA. PSA, $30 \mathrm{kDa}$ serine protease, is a serum marker for prostate cancer, the most prevalent form of cancer in men (21). The current PSA assays are based on sandwich ELISA, which is sensitive enough to detect $0.1 \mathrm{ng} / \mathrm{mL}$ PSA in the sample. PSA concentration is 4-5 $\mathrm{ng} / \mathrm{mL}$ in the blood of healthy donors and $10 \mathrm{ng} / \mathrm{mL}$ and higher in patients with prostate cancer. Sandwich immunoassay for PSA has been carried out using microchips with immobilized primary antibodies. These biochips were treated with solutions containing known concentrations of PSA or blood serum samples and developed with Cy3-labeled secondary antibodies. The observed fluorescence signals from gel elements with immobilized antibodies were proportional to PSA concentration (Figure 3A). Low background signals were achieved by the pretreatment of microchips with blocking buffer containing BSA and sucrose or polyvinylalcohol. As can be seen from Figure 3, panels B and C, the fluorescence intensities clearly indicate the elevated level of PSA in blood sera of cancer patients. The sensitivity of PSA assay was $0.5 \mathrm{ng} / \mathrm{mL}$, which is sufficient for diagnostic purposes.

\section{Protein-Protein Interactions}

Barnase. Detailed studies of the influence of protein modification and immobilization in a gel on its functional properties were carried out with ribonuclease barnase. It consists of three identical subunits with a molecular mass of $12.3 \mathrm{kDa}$ each, containing nine amino groups, and has no cysteine residues. The modification of barnase by MAOSu under different conditions resulted in the introduction of from one to nine methacrylic groups per subunit. The

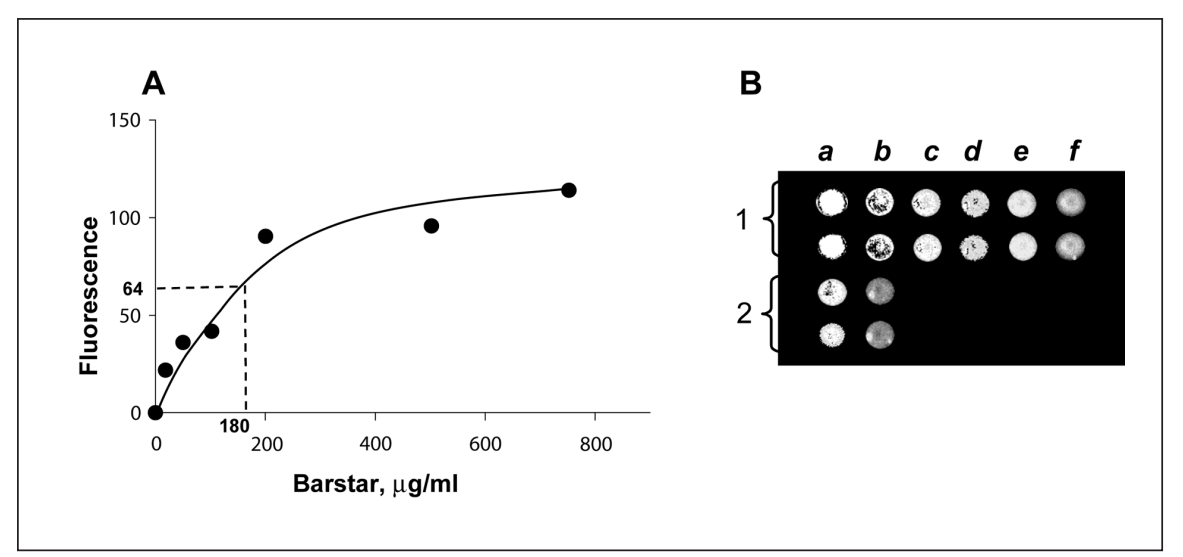

Figure 4. Quantitative assay of the expression of recombinant barstar in human embryo cells. Calibration curve for quantification of barstar. The concentration of barstar is $180 \pm 30 \mu \mathrm{g} / \mathrm{mL}$ (A). Fluorescence image after development with Texas Red-labeled barnase (B). Microchip arrangement: 1 - immobilized lysate with barstar, $750(a), 500(b), 200(c), 150(d), 100(e)$, and $50(f) \mu \mathrm{g} / \mathrm{mL} ; 2$ - lysate of recombinant cells $(a)$ and control lysate without barstar $(b)$ 

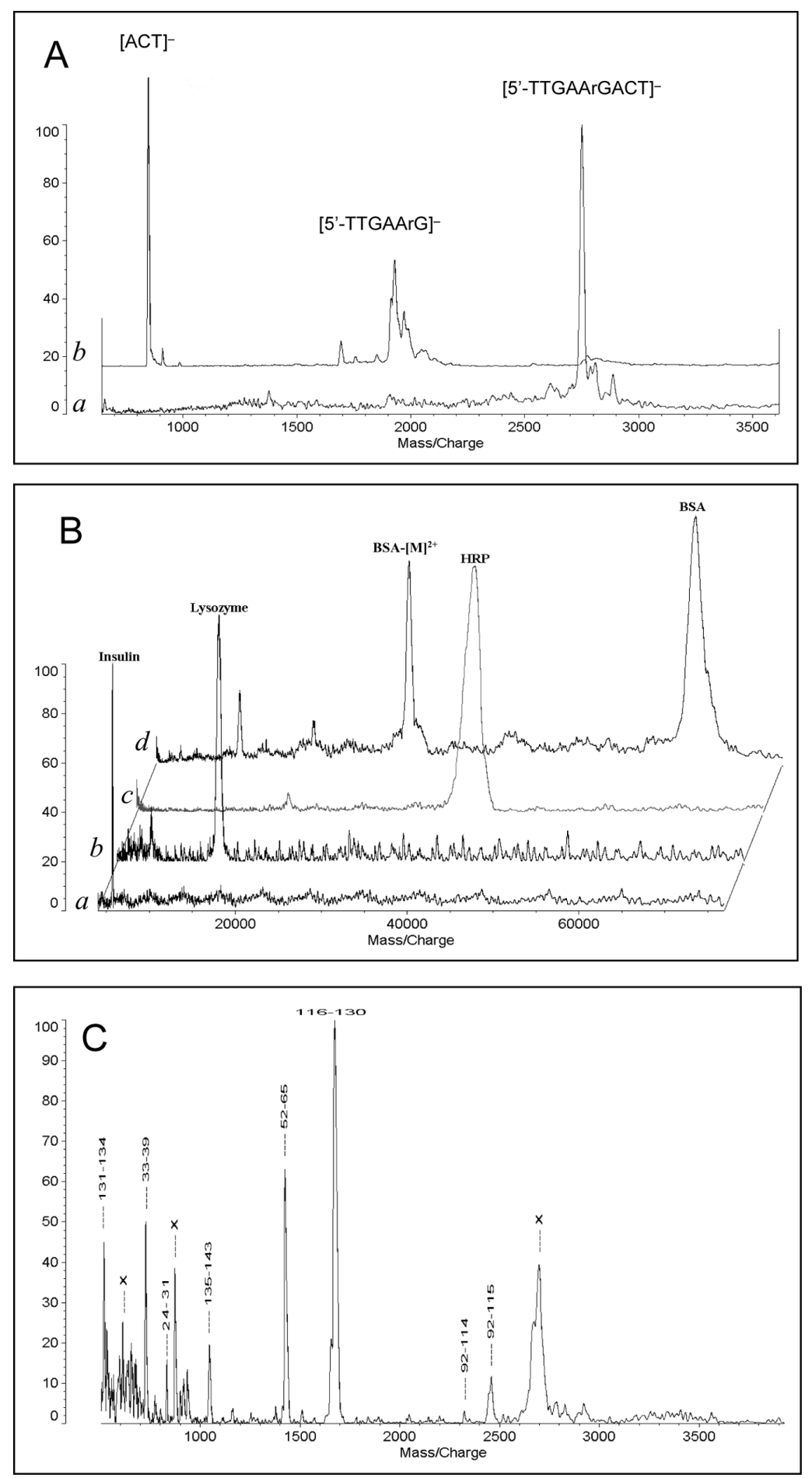

Figure 5. MALDI-TOF mass spectra obtained directly from microchip gel elements. (A) Mass spectrum of 5'-TTGAA-(ribo-G)-ACT-3' oligonucleotide after incubation with chip-immobilized barnase. $a$, control gel pad without barnase and $b$, immobilized barnase, $0.1 \mathrm{mg} / \mathrm{mL}$, hydrolysis for $1 \mathrm{~min}$ at room temperature. (B) Mass spectra of biotinylated proteins after their interaction with chip-immobilized avidin. The proteins used were insulin $(a)$, lysozyme $(b)$, HRP $(c)$, BSA $(d)$. (C) Mass spectrum of peptides formed after the tryptic digestion of chip-immobilized lysozyme in m/z 500-3500 region. The numbers indicate the position of peptide in lysozyme sequence; and $\mathrm{X}$, peaks from the self-hydrolysis of trypsin or non-identified peaks. 
degree of immobilization of barnase did not depend on the amount of modified amino groups from one to five per subunit and was about $70 \%$ (Table 1).

Barnase forms a stable equimolar complex with its protein inhibitor barstar (22). When the chips were treated with Texas Red-labeled barstar, the highest fluorescent signal was observed for microchip-immobilized barnase, in which only one amino group was modified. The increase in the extent of modification led to a decrease in the ability to bind barstar by $20 \%$ for barnase with five modified groups and to complete inactivation if all nine amino groups were modified with methacrylic group (data not shown).

Quantitative assay of recombinant barstar in cell lysates. Barnase-barstar interactions were used to analyze the amount of recombinant barstar in human embryo cells expressing the barstar gene (Figure 4). Cell lysates were immobilized on a microchip, and the amount of barstar in the lysates was measured by binding with fluorescently labeled barnase. The microchip contained gel pads with immobilized lysate of recombinant cells, control (immobilized lysate of the same cells without the barstar gene), and cell lysates with known concentrations of barstar added to the control lysates to construct the calibration curve. For the gel elements with lysate under study, the fluorescence signal corresponded to 180 $\pm 30 \mu \mathrm{g}$ barstar in $1 \mathrm{~mL}$ of lysate. It should be noted that the quantitative assay was carried out with crude lysate after only one step of purification-DNA precipitation.

\section{Enzymatic Reactions on the Microchips}

Barnase is G-specific ribonuclease, which can also cleave RNA at other ribonucleotides with less efficiency. To check the enzymatic activity of barnase on a chip, the $5^{\prime}$-TTTT-(ribo-UUU)TTTTT-3' and 5'-TTGAA-(ribo-G)ACT-3' oligonucleotides were applied to gel elements with chip-immobilized barnase containing one methacrylic group. As a negative control, gel elements with no immobilized barnase were used. The immobilized enzyme completely split the ribo-G-containing oligonucleotide in less than $1 \mathrm{~min}$ at room temperature (Figure 5A) according to the MALDI-TOF MS analysis. The total hydrolysis of the ribo-U-containing oligonucleotide occurred in several hours at room temperature (data not shown). The results clearly indicate that immobilized barnase maintains both its ribonuclease activity and substrate specificity.

HRP. The enzyme was allowed to diffuse into empty gel elements of the microchips, and the enzymatic activity was determined as the intensity of light originating from gel elements after the addition of chemiluminescent substrates (luminol and $\mathrm{H}_{2} \mathrm{O}_{2}$ ). The specific activity of non-immobilized peroxidase was $10^{5}$ arbitrary units/mg. The activity of HRP immobilized within gel elements was measured under the same conditions, and the specific activity of immobilized HRP was calculated taking into account that the immobilization degree of HRP was $40 \%$ (Table 1) $\left(7 \times 10^{4}\right.$ arbitrary units $\left./ \mathrm{mg}\right)$. Thus, we may conclude that the gel-immobilized HRP retained $70 \%$ of its initial enzymatic activity.

Proteolytic hydrolysis. The hydrolysis of proteins was carried out inside individual gel elements. A drop of trypsin solution was applied to elements containing immobilized lysozyme, and the hydrolysis was carried out in each gel element separated from each other by glass hydrophobic surface and air. The resulting peptides were analyzed by MALDI-TOF MS directly from gel ele- ments. Mass spectrum of lysozyme tryptic digestion products showed the presence of a set of peptides (Figure 5B). The spectrum consisted of 26 peaks. After subtracting the peaks originating from the self-hydrolysis of trypsin, 14 peaks were identified as peptides, resulting from the complete hydrolysis of lysozyme plus peptides with a single uncut site. The molecular masses of peptides were introduced into the PeptIdent program from the SWISSPROT protein database for the analysis of "peptide fingerprints." The search was carried out for proteins with molecular masses 12 880-15750, tryptic hydrolysis, mass determination accuracy $\pm 5 \mathrm{Da}$, and cysteines in reduced form. As a result, chicken lysozyme with the molecular mass of 14313 was identified with $75 \%$ accuracy.

This experiment indicated that covalently immobilized protein is accessible for proteolytic hydrolysis inside the gel elements. The procedure developed for the MALDI-TOF monitoring of peptide hydrolyzates directly from gel elements can be used for the identification of proteins. The digestion products were also eluted from gel elements and analyzed with HPLC (data not shown). The HPLC analysis corroborated the mass spectrometry data.

\section{Protein-Ligand Interaction on the Chip}

Avidin-biotin. Solutions of biotiny-

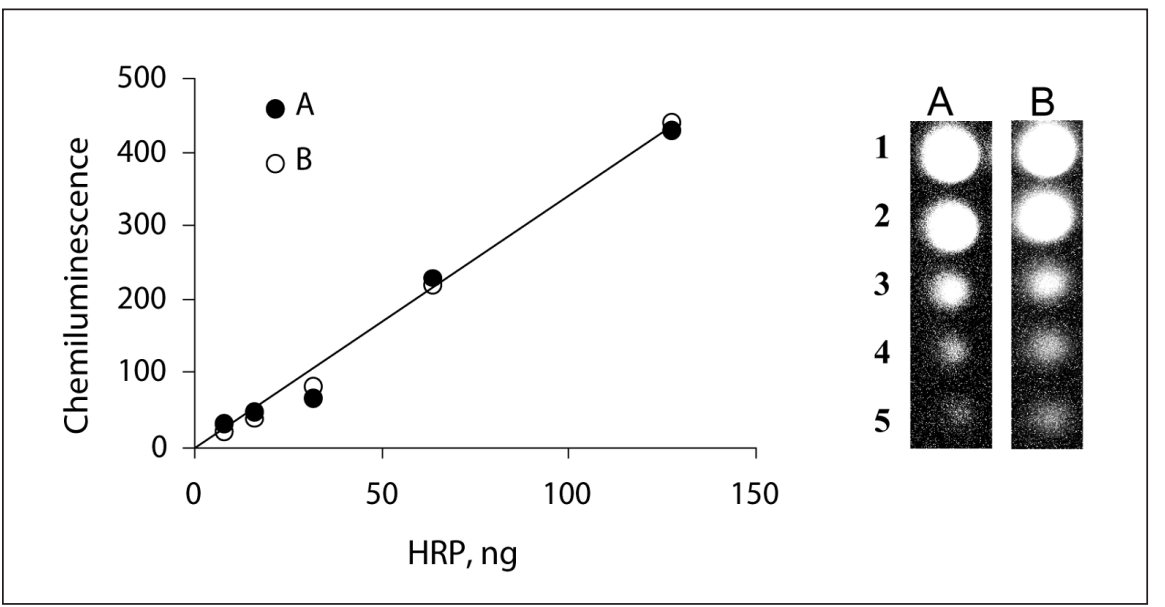

Figure 6. Stability of gel-immobilized HRP. Dependence of chemiluminescence signals from gel pads on the concentration of immobilized HRP. The concentration was 128 (1), 64 (2), 32 (3), 16 (4), and 8 (5) ng per gel pad. The signals were measured immediately after gel polymerization (A) and after six months storage in a humid chamber in the presence of $40 \%$ glycerol (B). 
lated proteins were applied onto a chip with gel elements $0.6 \mathrm{~mm}$ in diameter containing immobilized avidin. The proteins were detected by MALDI-TOF MS directly from gel elements (Figure 5C).

Complex of Ni-NTA with $\mathrm{His}_{6}$ containing proteins. Small ligands containing unsaturated groups can be successfully immobilized on a microchip and used for the specific binding of proteins. NTA was preliminarily modified with an $N$-methacryloyl group and immobilized within the matrix of microchip elements. The incubation of the microchip with $\mathrm{NiSO}_{4}$ solution resulted in the coating of gel matrix with $\mathrm{Ni}$ atoms that are used for the specific binding of oligohistidinetagged recombinant proteins. GFP with a $\mathrm{His}_{6}$-fragment at the $\mathrm{N}$-terminus was applied to Ni-NTA gel elements. NiNTA-GFP complex was detected both by MALDI-TOF MS and fluorescent analysis. GFP itself contains an intrinsic fluorescent group, and fluorescent signals were obtained without the introduction of any additional fluorescent label into the protein (data not shown).

\section{Stability of On-Chip Immobilized Proteins}

The gels themselves sustain fluctuations in temperature, and chips with immobilized proteins can be stored for at least six months with no loss of biological activity. In general, the stability of microchips is determined by the stability of gel-immobilized compounds. While oligonucleotide microchips can be stored dry at room temperature, most protein chips should be kept in a humid chamber at $10^{\circ} \mathrm{C}$ in the presence of $20 \%-40 \%$ glycerol to avoid protein denaturation.

The stability of chip-immobilized proteins was investigated in a series of experiments. The chemiluminescent signal from as little as $8 \mathrm{ng}$ HRP could be seen six months after immobilization, indicating that the protein maintained its biological activity (Figure 6). Calibration curves for the PSA assay with the sandwich method were constructed for freshly prepared microchips, and six months later, the sensitivity of the assay had not changed, indicating the good stability of immobilized antibodies in a gel (Figure 3 ).

\section{DISCUSSION}

In this report, we describe a versatile, efficient, and rather simple platform for the manufacturing and use of the second generation of gel-based protein chips (IMAGE chips). The manufacturing procedure consists of three steps. An even simpler 3-D generation procedure consists of two steps, com- bining protein modification and gel polymerization into one step. The quality of the second and third generations of the protein chips is similar. The thirdgeneration procedure is adopted for commercial mass production due to its simplicity. Importantly, the same procedure can be used for manufacturing and analysis of protein chips, oligonucleotide and DNA chips, as well as 


\section{Research Report}

biochips containing immobilized both oligonucleotides and proteins. Such chips can find applications, for example, in PCR immunoassays (23).

The chosen conditions for protein immobilization by copolymerization (use of methacrylamide instead of acrylamide and carrying out the reaction at 350 instead of $254 \mathrm{~nm}$ ) resulted in the production of porous, temperature-stable, and mechanically stable gels. The immobilization within the gel stabilizes the proteins, and the protein chips can be stored for several months. Copolymerization is an efficient procedure that results in the immobilization of proteins in a high yield (Table 1). Because immobilized molecules are fixed with strong covalent bonds, they are not removed even after intensive washing, and the amount of protein inside the gel elements remains constant. Even at high concentrations of immobilized proteins, the molecules are separated from each other and from the hydrophobic surface of the carrier that prevents their aggregation and loss of biological activity. The protein chips show negligible fluorescence background, low nonspecific protein binding, and can be used repeatedly. Instead of being chemically immobilized within the gel pads, proteins can be specifically bound to some ligands. For example, biotin and $\mathrm{Ni}$ NTA-modified gels were used for the immobilization of avidin- and oligohistidine-tagged proteins.

We have demonstrated several different applications of IMAGE protein chips. The quantitative analysis of proteins or other compounds bound to a protein chip can be performed using fluorescence and chemiluminescence measurements. Antibody microchips can be used for the direct quantitative analysis of fluorescently labeled proteins or in a sandwich assay with labeled secondary antibodies. The quantitative analysis of proteins can be carried out even in complex mixtures. For example, the presence of the prostate cancer antigen was measured quantitatively in whole blood with an antibody chip. On the other hand, total protein of the mammalian cell lysate was immobilized in on a biochip, and the presence of expressed recombinant barstar in the lysate was determined quantitatively with fluorescently labeled barnase.

Mass spectrometry provides an efficient qualitative method for the identification and analysis of bound molecules. In this case, no labeling of analyzed material is needed. Such analysis can be carried out directly from gel elements of the protein chips and can be of interest for the mass screening of different compounds that bind specifically with microchip-immobilized proteins. Detailed characterization of the bound proteins can be carried out by the analysis of their tryptic 
digests. The digestion is performed in individual gel elements with no crosscontamination from adjacent ones. This mass spectrometry analysis of protein peptides on a chip can be useful in proteomics for the identification of specifically interacting proteins.

As was shown here and previously (9), the protein chips can be used for substrate and inhibitor analysis of immobilized enzymes. Kinetic measurements of the enzyme activity can be carried out on microchips in real time directly in the reaction chamber.

The experiments presented in this paper suggest that the protein biochip can be easily manufactured by copolymerization. The proteins preserve their functional activity in biochips for several months. The protein chip can provide a versatile tool in different fields of proteomics and diagnostics.

\section{ACKNOWLEDGMENTS}

The authors are grateful to Dr. V.S. Prassolov (EIMB) and to Drs. T.V. Osipova and T.P. Ryabykh (the Russian Oncological Scientific Center, Moscow, Russia) for the biological samples and fruitful discussions. We also thank V.V. Chupeeva, O.A. Diabina, and E.Ya. Kreindlin for the help in microchip manufacturing, A.V. Chudinov for the synthesis of fluorescent dyes, the mathematical group of the Center of Biological Microchips (D.V. Prokopenko, A.Yu. Turygin, and V.R. Chechetkin) for the help in mathematical calculations of experimental data and presentation of fluorescence data, and A. Kolchinsky, Health Front Line, Ltd. (Champaign, IL, USA) for the assistance in the preparation of the paper. We are also grateful to Dr. Ivo Glynne Gut, Center of National Genotypage, Evry, France, and B. Fleutiaux, Counselor on Science and Technology, French Embassy in Russia, for the helpful discussions and facilitation of the RussianFrench collaborative research.

\section{REFERENCES}

1.Ekins, R.P. 1998. Ligand assays: from electrophoresis to miniaturized microassays. Clin. Chem. 44:2015-2030.

2.Lal, S.P., R.I. Christopherson, and C.G. dos
Remedios. 2002. Antibody arrays: an embryonic but rapidly growing technology. Drug Discov. Today 7:S143-S149.

3.Mirzabekov, A. and A. Kolchinsky. 2001. Emerging array-based technologies in proteomics. Curr. Op. Chem. Biol. 6:70-75.

4.Templin, M.F., D. Stoll, M. Schrenk, P.C. Traub, C.F. Vohringer, and T.O. Joos. 2002. Protein microarray technology. Trends. Biotechnol. 20:160-166.

5.Abbott, A. 2002. Betting on tomorrow's chips. Nature 415:112-114.

6.Mitchel, P. 2002. A perspective on protein microarrays. Nat. Biotechnol. 20:225-229.

7.Angenendt, P., J. Glokler, D. Murphy, H. Lehrach, and D.J. Cahill. 2002. Toward optimized antibody microarrays: a comparison of current microarray support materials. Anal. Biochem. 309:253-260.

8.Khrapko, K., Yu. Lysov, A. Khorlin, V. Shick, V. Florentiev, and A. Mirzabekov. 1989. An oligonucleotide hybridization approach to DNA sequencing. FEBS Lett. 256:118-122.

9.Arenkov, P., A. Kukhtin, A. Gemmel, S. Voloshchuk, V. Chupeeva, and A. Mirzabekov. 2000. Protein microchips: use for immunoassay and enzymatic reactions. Anal. Biochem. 278:123-131.

10.Guschin, D., G. Yershov, A. Zaslavsky, A. Gemmell, V. Shick, D. Proudnikov, P. Arenkov, and A. Mirzabekov. 1997. Manual manufacturing of oligonucleotide, DNA and protein microchips. Anal. Biochem. 250:203211.

11.Mirzabekov, A.D., A.Yu. Rubina, S.V. Pan'kov, and B.K. Chernov, Enhelhardt Institute of Molecular Biology of the RAS, Moscow, Russia. Method of immobilization of oligonucleotides, which contain unsaturated groups, in polymeric hydrogels on the formation of microchip. Russian Patent No. 2175972, November 20, 2001

12.Mirzabekov, A.D., A.Yu. Rubina, S.V. Pan'kov, A.N. Perov, and V.V. Chupeeva, Enhelhardt Institute of Molecular Biology of the RAS, Moscow, Russia. Composition for immobilization of biological macromolecules in hydrogels on forming of biochips, method for preparation of the composition, biochip and method for carrying out PCR on a biochip. PCT/RU 01/00445, priority of 25.07.2001.

13.Timofeev, E., S. Kochetkova, A. Mirzabekov, and V. Florentiev. 1996. Regioselective immobilization of short oligonucleotides to acrylic copolymer gels. Nucleic Acids Res. 24:3142-3148.

14.Vasiliskov, A.V., E.N. Timofeev, S.A. Surzhikov, A.L. Drobyshev, V.V. Shick, and A.D. Mirzabekov. 1999. Fabrication of microarray of gel-immobilized compounds on a chip by co-polymerization. BioTechniques 27:592-606.

15.Mirzabekov, A. and A. Kolchinsky. 2002. MAGIChip: properties and applications in genomic studies, p. 163-196. In D.J. Galas and S. McCormack (Eds.), Genomic Technologies: Present and Future. Functional Genomics Series, vol. 1. Caiser Academic Press, Wymondham, UK.

16.Barsky, Ya., A. Grammatin, A. Ivanov, E.
Kreindlin, E. Kotova, V. Barskii, and A. Mirzabekov. 1998. Wide-field luminescence microscopes for analyzing biological microchips. J. Opt. Technol. 65:938-941.

17.Barsky, V., A. Perov, S. Tokalov, A. Chudinov, E. Kreindlin, A. Sharonov, E. Kotova, and A. Mirzabekov. 2002. Fluorescence data analysis on gel-based biochips. J. Biomol. Screen 7:247-257.

18.Hermanson, G.T. 1996. Bioconjugate techniques, p. 137-166. In Bioconjugate Techniques, Part 1, Ch. 2. Academic Press, San Diego.

19.Mirzabekov, A.D., A.Yu. Rubina, and S.V. Pan'kov, Enhelhardt Institute of Molecular Biology of the RAS, Moscow, Russia. Composition for polymerization immobilization of biologically important compounds and method for its preparation. Patent PCT/RU $01 / 00420$, priority of 16.10 .2001 .

20.Stomakhin, A.A., V.A. Vasiliskov, E. Timofeev, D. Shulga, R.J. Cotter, and A.D. Mirzabekov. 2000. DNA sequence analysis by hybridization with oligonucleotide microchips: MALDI mass spectrometry identification of 5-mers contiguously stacked to microchip oligonucleotides. Nucleic Acids Res. 28:1193-1198.

21.Polascik, T.G., J.E. Oesterling, and A.W. Partin. 1999. Prostate specific antigen: a decade of discovery - what we have learned and where we are going. J. Urol. 162:293-306.

22.Schreiber, G. and A.R. Fersht. 1993. Interaction of barnase with its polypeptide inhibitor barstar studied by protein engineering. Biochemistry 32:5145-5150.

23.Niemeyer, C.M., M. Adler, B. Pignataro, S. Lenhert, S. Gao, S. Chi, L. Fuchs, and D. Blohm. 1999. Self-assembly of DNA-streptavidin nanostructures and their use as reagents in immuno-PCR. Nucleic Acids Res. 27:4553-4561.

Received 13 February 2003; accepted 5 March 2003.

\section{Address correspondence to:}

Dr. Andrei D. Mirzabekov

Engelhardt Institute of Molecular Biology

Russian Academy of Sciences

32 ul. Vavilova, 119991 Moscow, Russia

e-mail:amir@eimb.ru 